\title{
First report of Paramphistomum leydeni Näsmark, 1937 (Trematoda: Paramphistomidae) in Argentina, and re-examination of Cotylophoron cotylophorum sensu Racioppi et al. (1994)
}

\author{
R. E. F. SANABRIA ${ }^{1 *}$, S. R. MARTORELLI², J. R. ROMERO ${ }^{1}$
}

${ }^{1}$ Centro de Diagnóstico e Investigaciones Veterinarias, Facultad de Ciencias Veterinarias, Universidad Nacional de La Plata, Argentina, *E-mail: sanabriaref@cedivechascomus.com.ar; ${ }^{2}$ Centro de Estudios Parasitológicos y Vectores, Facultad de Ciencias Naturales y Museo, Universidad Nacional de La Plata - Consejo Nacional de Investigaciones Científicas y Técnicas, Argentina

\begin{abstract}
Summary
Cotylophoron cotylophorum and Balanorchis anastrophus are the only amphistomes of ruminants that have been described so far in Argentina. Recent observations suggest that $C$. cotylophorum could have been misclassified. To confirm this, we examined specimens, collected in Corrientes Province and classified by Racioppi et al. (1994) as Cotylophoron cotylophorum, and re-classified these as Paramphistomum leydeni Näsmark, 1937. Flukes collected from Zárate (Buenos Aires) were also studied and compared against the former, resulting in the same species. The present study reports the existence of $P$. leydeni in Argentina, modifies the previous classification of $C$. cotylophorum and suggests that, based on the evidence of the amphistomes described so far, $P$. leydeni would be the most prevalent species in cattle of Argentina.
\end{abstract}

Keywords: Paramphistomum leydeni; Cotylophoron cotylophorum; cattle; Argentina

\section{Introduction}

At present, there are only two known amphistome species from ruminants in Argentina: Balanorchis anastrophus (Fischoeder 1901), described by Szidat and Ostrowski in 1962 and Cotylophoron cotylophorum (Fischoeder 1901), first reported by Racioppi et al. (1994). Rodriguez Armesto et al. (2002) and Bulman et al. (2002) mentioned this last report in further studies with cattle, and Sanchez et al. (2005) did likewise in cattle and sheep. Despite these descriptions were based on the previous identifications of C. cotylophorum, detailed morphological characteristics were not included.

Exhaustive descriptions of Cotylophoron sp. (Eduardo 1985), as well as reports of amphistomes in the neighboring countries such as Uruguay and Brazil (Gonzalez Medina, 1975; Freyre, 1987; Costa et al., 1999), led to believe that the species identified in Argentina as $C$. cotylophorum, could belong to another species.

The main purpose of this paper was to re-examine some of the original specimens used by Racioppi et al. (1994), which were identified as $C$. cotylophorum, and, considering histological and morphological characteristics, define its taxonomical classification. Besides, similar paramphistomid specimens (collected from cattle in another region of Argentina) are also described.

\section{Materials and Methods}

Eight formalin preserved samples of $C$. cotylophorum collected by Racioppi et al. (1994) from cattle in a slaughterhouse located in San Cayetano, Corrientes $\left(27^{\circ} 25^{\prime} \mathrm{S}\right.$, $\left.58^{\circ} 39^{\prime} \mathrm{W}\right)$, were evaluated for a second time.

These specimens were compared with thirteen flukes obtained from cattle from Zárate (Buenos Aires) $\left(34^{\circ} 05^{\prime} \mathrm{S}\right.$, $\left.59^{\circ} 05^{\prime} \mathrm{W}\right)$. Specimens were collected during the necropsy of a calf. These were placed in hot saline solution, transferred to formalin solution $(10 \%)$, and preserved until their subsequent study.

Both types of amphistomes were stained with hydrochloric carmine, dehydrated by series of ethanol, cleared in clove oil and mounted in Canada balsam. Three specimens from each of the two collection sites were placed in $70 \%$ ethanol, dehydrated, embedded and sectioned $(4-5 \mu \mathrm{m})$ following standard histological procedures. Sections were stained with hematoxylin and eosin to search for muscular structures of taxonomical importance such as ventral sucker, pharynx and terminal genitalia.

The nomenclature suggested by Eduardo (1982a) was used to describe the muscular structures.

Measurements taken from whole mounted specimens and histological sections were expressed in millimeters by maximum and minimum (Table 1). 
Voucher specimens were deposited in the Helminthological collection of La Plata Museum, National University of La Plata, Argentina. mounted and flattened samples are shown in Table 1.

Body conical, pink colored when fresh. Small tegumental papillae are present in the first third of the body surface,

Table 1. Measures by maximum and minimum values ( $\mathrm{mm}$ ) of P.leydeni from Corrientes and Buenos Aires, and comparission to C.cotylophorum description (Racioppi et al., 1994) and Eduardo's revision (1982b)

\begin{tabular}{|c|c|c|c|c|c|c|}
\hline & \multicolumn{2}{|c|}{ Corrientes } & \multicolumn{2}{|c|}{ Buenos Aires } & \multirow{2}{*}{$\begin{array}{l}\text { Cotylophoron } \\
\text { cotylophorum } \\
\text { Racioppi et al., } \\
1994\end{array}$} & \multirow{2}{*}{$\begin{array}{l}\text { Paramphistomum } \\
\text { leydeni } \\
\text { Eduardo, } 1982 \mathrm{~b}\end{array}$} \\
\hline & $M H S(n=3)$ & $S \& F(n=5)$ & $M H S(n=3)$ & $S \& F(n=10)$ & & \\
\hline Body length & $5.88-6.42$ & $7.36-10.86$ & $6.20-8.36$ & $7.34-9.94$ & $7-13$ & $4.1-6.8$ \\
\hline $\begin{array}{l}\text { Body width } \\
\text { Acet diameter }\end{array}$ & $\begin{array}{c}3-3.12 \\
1.38-1.69\end{array}$ & $\begin{array}{l}3.67-4.48 \\
1.60-2.16\end{array}$ & $\begin{array}{l}2.02-2.61 \\
1.50-1.70\end{array}$ & $\begin{array}{l}2.83-4.52 \\
1.66-2.55\end{array}$ & $1.6-2.1$ & $\begin{array}{c}2-3.35 \\
1.28-1.81\end{array}$ \\
\hline Pharynx lenght & $0.7-0.86$ & $0.75-1.02$ & $0.64-0.84$ & $0.66-0.96$ & $0.7-0.85$ & $0.57-0.84$ \\
\hline Pharynx width & $0.44-0.55$ & $0.67-0.94$ & $0.57-0.61$ & $0.65-1.00$ & & $0.51-0.58$ \\
\hline Oesophagus & $0.47-0.57$ & $0.49-0.75$ & $0.57-0.81$ & $0.49-1.20$ & & $0.51-0.78$ \\
\hline AT long & $1.04-1.39$ & $1.13-1.96$ & $0.98-1.20$ & $0.89-2.00$ & & $0.53-0.97$ \\
\hline AT Wide & $1.3-1.35$ & $1.76-2.19$ & $1.00-1.36$ & $1.10-2.66$ & & $1.01-1.54$ \\
\hline PT long & $0.6-0.7$ & $0.98-1.86$ & $0.80-0.91$ & $0.78-1.63$ & & $0.53-0.93$ \\
\hline PT Wide & $1.66-2$ & $2.32-3.48$ & $1.50-1.75$ & $1.81-3.15$ & & $0.83-1.96$ \\
\hline Pars prostática & $0.20-0.26$ & $0.24-0.44$ & $0.28-0.40$ & $0.20-0.44$ & & $0.19-0.32$ \\
\hline Ovary diameter & $0.58-0.69$ & $0.61-0.94$ & $0.45-0.61$ & $0.61-1.00$ & $0.5-0.62$ & $0.28-0.55$ \\
\hline $\begin{array}{l}\text { Ratio Acetabulum- } \\
\text { Body lenght }\end{array}$ & $1: 3.8-4.3$ & $1: 3.5-5.7$ & $1: 4.1-4.9$ & $1: 2.9-5.3$ & & $1: 3-3.7$ \\
\hline $\begin{array}{l}\text { Ratio pharynx- } \\
\text { Body lenght }\end{array}$ & $1: 7.5-8.4$ & $1: 8.5-12.8$ & $1: 9.7-11.2$ & $1: 8.8-11.3$ & & $1: 6-8.6$ \\
\hline $\begin{array}{l}\text { Ratio pharynx- } \\
\text { acetabulum } \\
\text { Muscular fibers }\end{array}$ & $1: 1.9$ & $1: 1.8-2.7$ & $1: 2-2.5$ & $1: 1.9-3.9$ & & $1: 1.9-2.5$ \\
\hline D.E.C. 1 & $10-15$ & & $12-14$ & & & $10-14$ \\
\hline D.E.C. 2 & $27-33$ & & $26-30$ & & & $34-39$ \\
\hline D.I.C. & $38-41$ & & $36-44$ & & & $38-44$ \\
\hline V.E.C. & $13-15$ & & $11-15$ & & & $16-20$ \\
\hline V.I.C. & $48-53$ & & $42-55$ & & & $47-50$ \\
\hline M.E.C. & $13-16$ & & $16-23$ & & & $14-26$ \\
\hline
\end{tabular}

MHS - mean histological sections; S\&F - stained and flattened; AT - anterior testicle; PT - posterior testicle; DEC - dorsal external circular; VEC - ventral external circular; DIC - dorsal internal circular; VIC - ventral internal circular; MEC - Median external circular

\section{Results}

\section{Description}

Paramphistomum leydeni Näsmark, 1937

Syn. Cotylophoron cotylophorum (sensu Racioppi et al., 1994). (Figs 1 - 9).

Locality: San Cayetano, Corrientes $\left(27^{\circ} 25^{\prime} \mathrm{S}, 58^{\circ} 39^{\prime} \mathrm{W}\right)$, and Zárate, Buenos Aires $\left(34^{\circ} 05^{\prime} \mathrm{S}, 59^{\circ} 05^{\prime} \mathrm{W}\right)$, Argentina.

Host: Bos taurus Linnaeus, 1758.

Site of infection: rumen

Specimens deposited: 5725 and 5726

The description is based on the 8 specimens from Corrientes ( 5 mounted ones, and the histological sections of 3 specimens) and the 13 specimens from Buenos Aires (10 mounted specimens, and the histological sections of other $3)$. Measurements taken on histological sections and reaching the genital pore. Acetabulum subterminal, of Paramphistomum type, characterized by a double row of dorsal external (D.E.C.) muscular units: D.E.C. 1, and D.E.C. 2, the former greater in size than the latter and inversely as to the number of muscular units.

Pharynx of the Liorchis type (sensu Näsmark 1937), with internal surface covered with papillae, and without bulb or posterior sphincter. Caeca almost straight running on the lateral sides of body, and reaching the acetabulum level, without medial meeting.

Testes in tandem, slightly lobed. Seminal vesicle long, pars musculosa and pars prostatica present. Ovary post-testicular. Mehlis' gland close to ovary. Laurer's channel present. Vitellaria laterally extended, from middle level of pharynx to anterior half level of the acetabulum. Genital pore opens at level of caecal bifurcation. Terminal genitalium of Leydeni type (sensu Eduardo 1982a) in median sagittal section. 

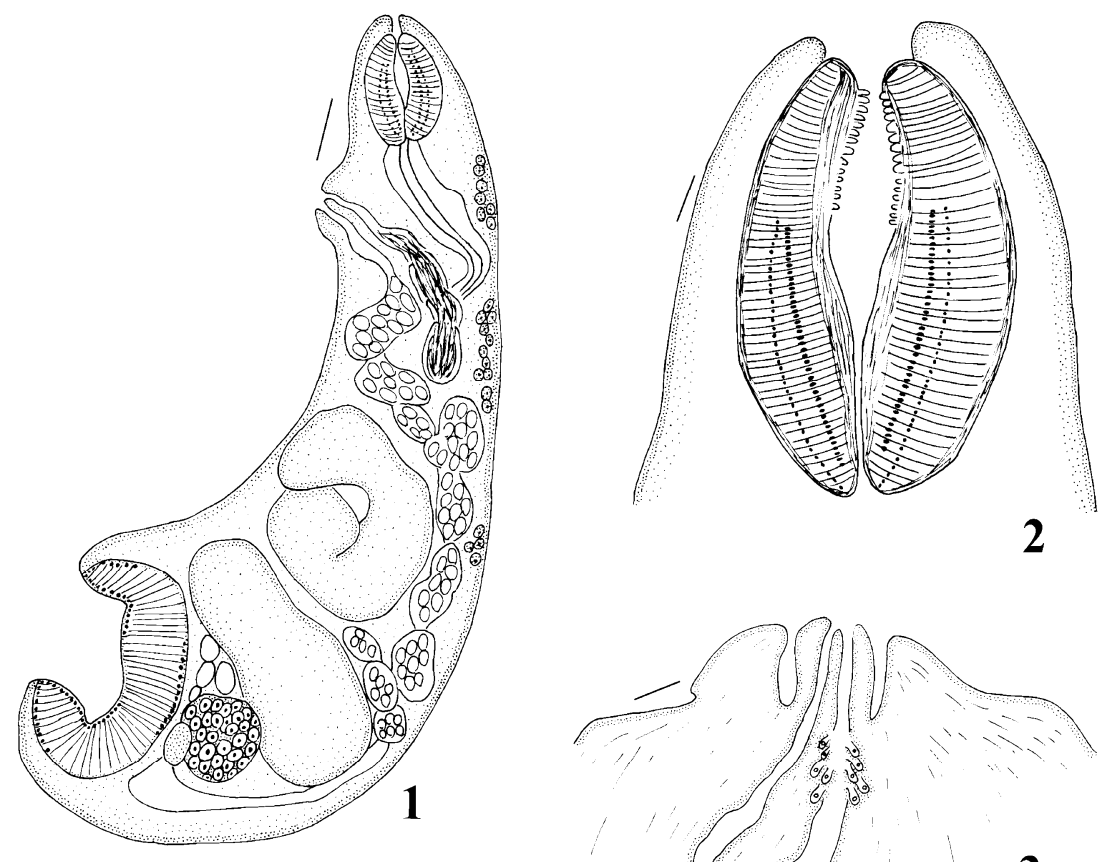

2

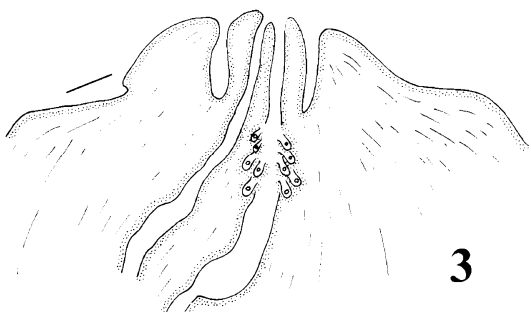

Figs. 1 - 3. Paramphistomum leydeni Näsmark, 1937 from Corrientes. 1 - Whole worm in sagittal view scale bar $=500 \mu \mathrm{m} .2$ - Pharynx scale bar $=100 \mu \mathrm{m} 3-$ Terminal genitalium and pars prostatica scale bar $=100 \mu \mathrm{m}$
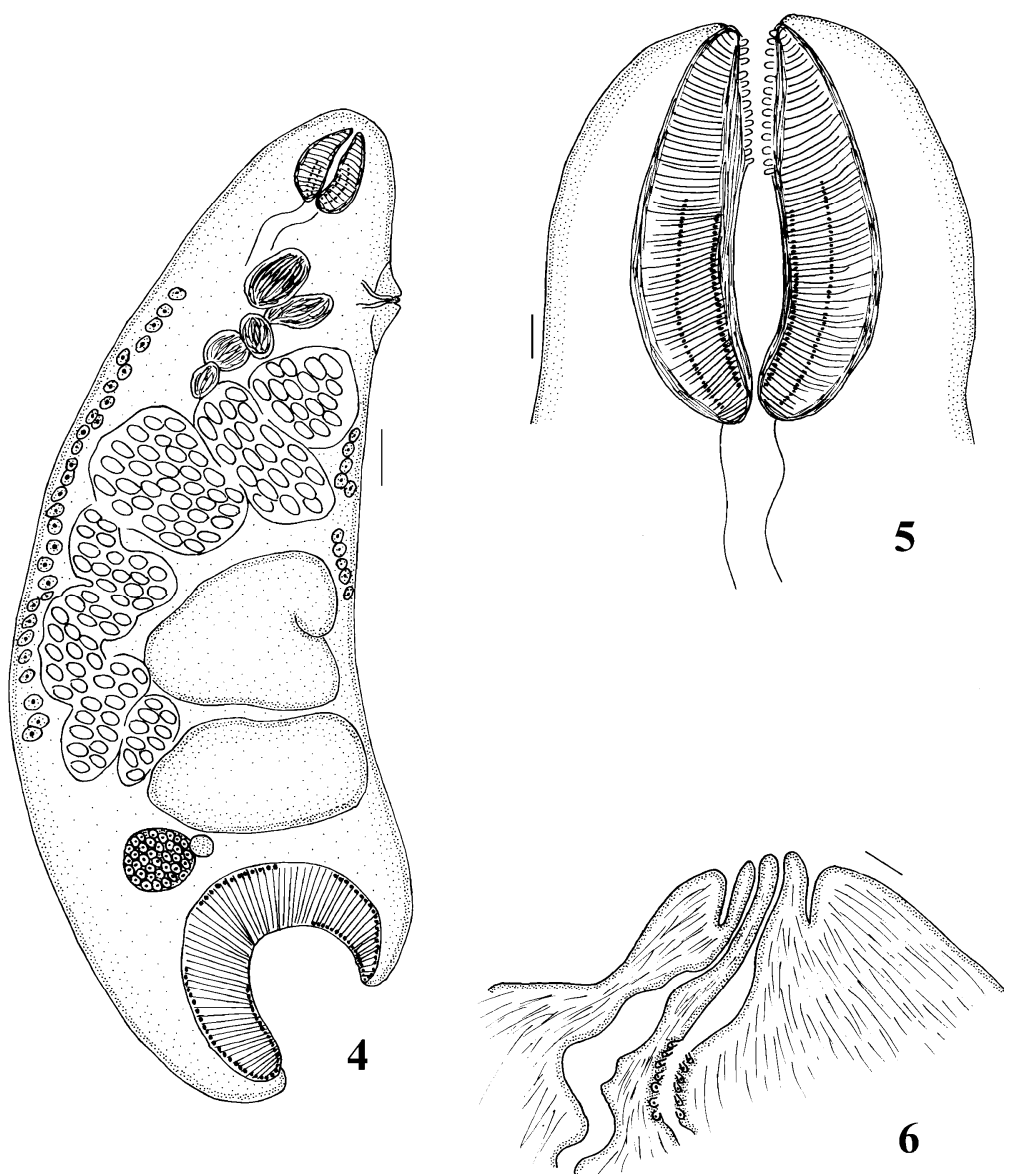

Figs. 4 - 6. Paramphistomum leydeni Näsmark, 1937 from Buenos Aires. 4 - Whole worm in sagittal view scale bar=500 $\mu$ m; 5 - Pharynx scale bar $=100 \mu \mathrm{m} ; 6$ - Terminal genitalium and pars prostatica scale bar $=100 \mu \mathrm{m}$ 

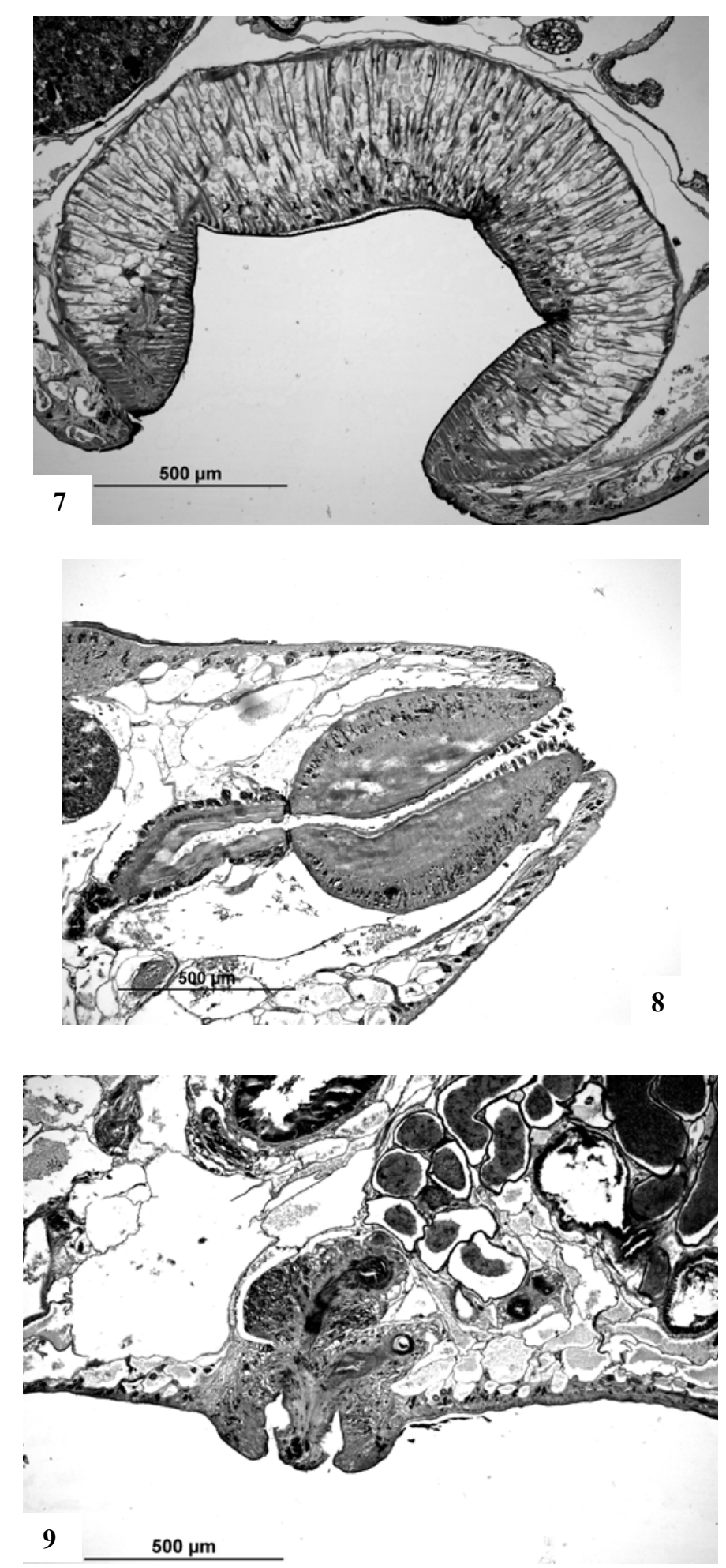

Figs. 7 - 9. Paramphistomum leydeni Näsmark, 1937 from Corrientes. 7 - acetabulum, medial sagittal sections; 8 - pharynx and oesophagus, medial sagittal sections; 9 - terminal genitalium, medial sagittal sections. H\&E, scale bar $=500 \mu \mathrm{m}$

\section{Discussion}

The amphistomes previously classified as $C$. cotylophorum by Racioppi et al. (1994), showed no similarities with the typical characteristics of the genus (Eduardo, 1985; Sey, 1991), for instance, the absence of a true genital sucker (in
C. cotylophorum, this structure is almost the same size as the pharynx).

The presence of a Paramphistomum type of acetabulum and a Liorchis type of pharynx, suggest that the studied specimens fit into the genus Paramphistomum. Within this genus and taking into account the pharynx type, the termi- 
nal genitalia structure (Leydeni type), the measures and general relations of the body and the characteristics of the muscular packages of the pharynx and acetabulum (Table 1), the amphistomids previously reported by Racioppi et al. (1994) were included in the species Paramphistomum leydeni.

The morphological features and dimensions of the both groups of amphistomes studied (re-examined specimens by Racioppi et al. (1994), and new collected specimens from Buenos Aires), were coincident with the descriptions of P. leydeni (Näsmark 1937) by Eduardo (1982b), and other papers that refer to this species (Sey, 1991; Costa et al., 1999). In both cases, measures of mounted specimens are greater than those of histological cuts, due to the fact that the width of the parasites increases when they are compressed to observe the internal structures.

The specimens found in hosts from Buenos Aires resembled those from Corrientes in their main morphological characteristics, showing only some minor differences in the length and width of the body.

According to data from anamnesis, the Zárate (Buenos Aires) herd had never received animals from Corrientes or nearby regions. Thus, it is possible that the cycle of P.leydeni had developed within the farm itself.

Even with the existence of Cotylophoron travassosi (Costa \& Guimaraes, 1992), described in neighboring Brazil, at this moment there is no firm evidence to support the actual presence of this genus in Argentina. Therefore the authors believe that the vast majority of the descriptions of the genus Cotylophoron published in Argentina could belong to Paramphistomum. In any case, the existence of other amphistomes in Argentina cannot be excluded, nor the existence of other species of the Paramphistomum sp. At present however, P. leydeni appears to be the most ubiquitous species in Argentina.

\section{Acknowledgements}

We are grateful to Dr. Salcedo Eduardo for his invaluable revision of original specimen photos and Drs. Racioppi and Alvarez (Departament of Veterinary Parasitology, Universidad Nacional del Nordeste), for providing the samples of specimens of Cotylophoron cotylophorm originally described. To Drs. D. Eiras and G.M. Bulman, for his input and revision of the manuscript in English.

\section{References}

Bulman, G., Caracostantógolo, J., Lamberti, J. C., ZENÓn, A., BALBIANI, G. (2002): Cotylophoron cotylophorum (Fischoeder, 1901) (Digenea: Paramphistomidae), trematodo del rumen bovino en Argentina. Vet. Argent. 19: $673-682$

Costa, H. M. A., Guimaraes, M. P. (1992): Cotylophoron Travassosi sp. n. (Trematoda - Paramphistomidae) from cattle. Mem. Inst. Oswaldo Cruz. 87: 69 - 72

Costa, H. M. A., Guimaraes, M. P., Caldeira, M. C. M., MirandA M. A. (1999): Morphological aspects of Paramphistomum leydeni (Trematoda - Paramphistomata). Rev. Bras. Parasitol. Vet. 8: $67-70$

EDUARDO, S. (1982a): The taxonomy of the family Paramphistomidae Fischoeder, 1901 with special reference to the morphology of species occurring in ruminants. I. General considerations. Syst. Parasitol. 4: 7 - 57

EDUARDO, S. (1982b): The taxonomy of the family Paramphistomidae Fischoeder, 1901 with special reference to the morphology of species occurring in ruminants. II. Revision of the genus Paramphistomum Fischoeder, 1901. Syst. Parasitol. 4: 189 - 238

EDUARDO, S. (1985): The taxonomy of the family Paramphistomidae Fischoeder, 1901 with special reference to the morphology of species occurring in ruminants. V. Revision of the genus Cotylophoron Fischoeder, 1901. Syst. Parasitol. $7: 13-26$

FreYre, A. (1987): Paramphistomum cervi y P.ichikawai (Trematoda, Paramphistominae) en vacunos de Uruguay. Rev. Soc. Urug. Parasitol. 1: $35-40$

GonzÁlez MedinA, L. (1975): Paranfistomídeos (Trematoda) em ovinos (Ovis aries) do Rio Grande do Sul, Brasil. M S Thesis. Universidade Federeal Do Rio Grande Do Sul, Rio Grande Do Sul, Brasil, 34 pp.

NÄSMARK, K. E. (1937): A revision of the trematode family Paramphistomidae. Zool. Bidr. Uppsala 16: $301-565$

RACCiOpPi, O., LOMBARdero, O. J., MorienA, R. A. (1994): Cotylophoron cotylophorum (Fischoeder, 1901) (Trematoda, Paramphistomidae), nuevo parásito del bovino en la Argentina. Rev. Med. Vet. 75: 228 - 229

RODRiguez ARMESto R., BONNO BATTISTONi M.F., Peralta, J. L. (2002): Cotylophoron cotylophorum (Fischoeder, 1901): su presencia en bovinos del nordeste de la provincia de Santa Fe (Argentina). Vet. Argent. 19: $290-292$

SANCHEZ, R., SANABRIA, R., Romero, J. (2005): Hallazgo de Cotylophoron cotylophorum (Fischoeder, 1901) en las Provincias de Buenos Aires y Entre Ríos. Vet. Argent. 22: $111-116$

SEY, O. (1991): Handbook of the zoology of Amphistomes. CRC Press. Boca Raton, Florida, 480 pp.

SZIDAT, L., OstrowsKi DE NuÑEZ, M. (1962). Un trematode del estómago de rumiantes sudamericanos, Balanorchis anastrophus como cazador y predador. Neotropica. 8: $93-99$ 